\title{
Parenting Styles and Psychopathology: The Importance of Grandparents
}

\author{
Rui Manuel Carreteiro, ${ }^{1, *}$ and João Justo ${ }^{2}$ \\ ${ }^{1}$ National Institute of Psychology and Neurosciences, Alverca, Portugal \\ ${ }^{2}$ Faculty of Psychology, University of Lisbon, Lisbon, Portugal \\ "Corresponding author: Rui Manuel Carreteiro, National Institute of Psychology and Neurosciences, Apartado 33, 2616-907 Alverca, Portugal. Tel: +351-210965158, E-mail: \\ rui.carreteiro@inpn.pt
}

Received 2016 October 30; Accepted 2016 November 01.

\begin{abstract}
Background: Controversy exists regarding the role played by parent-children relationships for children's behavioral and psychosocial development. Crucial for some authors, others consider parenting styles as part of a more complex system. Less adaptive parenting styles are generally associated with children who have lower involvement at school and may contribute for psychopathology emergence.

Objectives: To investigate the contribution of parenting styles for the explanation of child psychopathology.

Hypothesis: Parenting styles (H1) and parents' childhood memories regarding parenting styles (H2) do contribute significantly for the explanation of statistical variance of children's psychopathology.

Method: Participants: 110 children (67 boys, 43 girls) aged 7-11 years $(M=9.22, S D=1.14)$ from schools in Portugal as well as 83 fathers and 86 mothers; Instruments: For parenting styles, the Portuguese version of EMBU memories of upbringing (for parents regarding their own parents), EMBU-P (for parents) and EMBU-C (for children) were used. To assess children's psychopathology the Portuguese version of $\mathrm{CBCL}$ was used.

Results: According to linear regressions, individual and family factors do contribute significantly for the explanation of all CBCL's indexes. EMBU-C regarding mothers' parenting styles only explains the Hyperactivity/Attention index. EMBU-P explains most of CBCL's indexes. Mothers' and Fathers' EMBU Memories of Upbringing explains the overall CBCL's indexes.

Conclusions: The explanation of children's psychopathology by parenting styles is not restricted to parents' representations regarding their own parenting styles nor to children's perceptions regarding parenting styles but extends to memories of parents regarding parenting styles used by their own parents. The ability of EMBU Memories of Upbringing to explain children's psychopathology seems to exceed the EMBU-P's and EMBU-C's capacity.
\end{abstract}

Keywords: Psychopathology, Children, Parents, Grandparents and Parenting Styles

\section{Background}

Families play an important role in the development and outbreak of children's behavior $(1,2)$. Early relationships are often identified as critical for child development $(3,4)$ and the quality of parental care is frequently considered the most important variable in children's development (4).

Several studies suggest that representations of parental involvement clearly affect the children's and adolescents' psychological well-being (5-7), particularly regarding self-esteem, self-confidence and interpersonal relationships (5-8).

Supportive parenting is positively related to the children's self-assessments (7) and parenting styles also interfere with personality dimensions (9). Belsky (10) argues that the parents' childhood experiences influence their behavior through the importance of developmental history on their personalities. Positive aspects of parent- children relationships are positively related with the increasing of children's psychological well being (5). According to Ghazinour et al. (11), parenting styles and personality traits are crucial for the explanation of psychopathology.

\subsection{Parenting Styles and Psychopathology}

Parenting styles are an important etiologic factor of behavioral problems. However, Ruchkin et al. (12) argued that they are only part of a more complex system, which is why the assessment of predisposition to behavioral problems should not stick to parenting styles.

Reviewing the association between parenting styles and children's psychopathology, Eisemann et al. (13) proposed an interactive model relating the emergence of psychopathological disorders with individual vulnerability, life events as well as biological, physiological and social factors.

Several studies support the relationship between parenting styles and external/internal behavioral problems 
such as (14-20): parental attitudes perceived by children, namely rejection and anxiety as well as influencing their external/internal behaviors (21).

Literature reveals relationships between the quality of parenting received by children and the development of extrinsic problems with data repeatedly documenting adverse effects of coercive and conflicted parenting as well as beneficial consequences of warm, sensitive and supportive parenting (22). Despite the fact that Muris et al. (19) did not find any association between parenting styles and internalizing behaviors, Rosa-Alcazar et al. (23), stated that girls show fewer symptoms and a more adaptive perception of parenting styles, compared to boys.

According to Perris (24), psychosocial determinants lead to dysfunctional parental behavior generating parental relationships characterized by negative experiences and subsequently, dysfunctional schemas about the self that would lead to psychopathological manifestations.

There seems to be no doubt regarding the impact of children's educational environments in situations ranging from adaptive functioning and school success to a large variety of children's and adolescents' problems such as drug abuse, aggressive behavior and anxiety (25). Parents with high levels of neuroticism and low extraversion tend to be more rejecting and less warm than other parents (26). Mothers' psychoticism correlates negatively with emotional affection and impulsivity/sensation seeking correlates with control exercised by them (26). On the contrary, outgoing and sociable parents reveal more support.

Martin et al. (27) describe a significant association between depression and paternal overprotection for boys and an absence of maternal care for girls. Similarly, analyzing the relationship between parenting styles and disorders of anxiety and depression in six European states, Heider et al. (28) found a homogeneous pattern in which low paternal/maternal care associates to mood disorders.

There is also evidence of a relationship between low acceptance/parental involvement and adolescent depression and a relationship between parents' authoritarian styles and adolescents' externalizing changes (29). Parents of anorectic patients presented higher scores in the care factor and lower scores in overprotection when compared with a control group (30).

Regarding drug abuse, parental disapproval and punishment is the most discriminatory factor concerning alcohol consumption in adolescents (31). Adolescents who perceive their parents as permissive regarding drugs have higher consumptions of tobacco, alcohol and cannabis (32). Villar et al. (32) described not only a positive correlation between antisocial behavior and permissive style but also a negative correlation between antisocial behavior and democratic style.

Families of children with Attention Deficit and Dyperactivity Disorder (ADHD) and families of children with behavioral problems share some characteristics with dysfunctional families; parental standards are often associated with disruptive behavior (33).

\subsection{Parenting Styles Across Generations}

Kovan et al. (34) suggest an intergenerational transmission of parental educational styles in which the previous generation psychologically influences attitudes and parental behavior of the next generation (35). Nowadays, most researchers assume that patterns of parental behavior and family functioning processes may be transmitted between generations (36).

According to Van IJzendoorn (37), the most basic model of intergenerational transmission can be described as the influence of parental educational styles of Generation 1(G1, grandparents) upon the development and parental behavior patterns of Generation 2 (G2, parents) which, in turn, influences the development of Generation 3 (G3, children). Another hypothesis predicts the influence of relevant aspects such as the interaction between grandparents and grandchildren (G1 and G3), overlooked in the first model.

Kerr et al. (38) found that: a) G1's parental style influences the adjustment of the G2's parenting; b) parental behavior patterns of G1 influence the parenting of both G2's early childhood and G3's childhood and c) the parenting received by $\mathrm{G} 2$ and $\mathrm{G} 3$ influences their behavior problems. Nevertheless, there may be continuities and gaps between parenting styles of several generations (39).

\section{Objectives}

Considering the previous theoretical framework, it appears that less adaptive parenting styles are generally associated with lower involvement in school activities and can lead to the up rise of psychopathology (5-7, 22). However, this contribution is undervalued by Ruchkin et al. (12) for whom parenting styles are only part of a larger system, not being clear whether parental attitudes lead to psychopathology or what psychopathology results from them. Therefore, the main goal of this research is to examine the role of parental styles in the uprising of child psychopathology.

According to this goal and previous literature review, it seems possible to propose the following hypothesis:

Hypothesis 1: Parental styles play an important role in the incidence of psychopathology in children.

Hypothesis 2: Parents' childhood memories regarding parenting styles play an important role in the incidence 
of children's psychopathology. The assumptions described for the previous hypothesis are now extended to children's grandparents.

\section{Methods}

\subsection{Participants}

Participants were 110 children (67 boys and 43 girls) aged from 7 - $11(M=9.22, S D=1.14)$, from several schools in Portugal (North, Central, South, Madeira and Azores), with 1 - 6 years of successful school education $(M=3, S D=1.22)$ and having a low level of failure at school $(\mathrm{M}=0.24, \mathrm{SD}=$ $0.70)$. Most of these children's parents participated in this study: 83 fathers aged $23-59(M=41.62, S D=6.90)$ and 86 mothers aged $25-49(\mathrm{M}=38.49, \mathrm{SD}=4.84)$.

\subsection{Instruments}

A socio-demographic questionnaire (SDQ) was developed to collect general information regarding the parents (gender, age, education, occupational status, marital status and socioeconomic status) and children (gender, age, education, number of academic failures and number of siblings).

Intellectual level was controlled using Raven's Colored Progressive Matrices - CPM (40, 41). Internal consistency analyses with our data yielded an excellent value ( $\alpha=$ $0.940, \mathrm{M}=29.53, \mathrm{SD}=5.75$ ).

To assess parenting styles, three different versions of the EMBU (Egna Minnen av Barndoms Uppfostran) were used.

The EMBU - My Memories of Upbringing assesses the frequency of certain educational practices during the subjects' childhood and adolescence regarding their father and mother separately over three factors: emotional support, rejection as well as overprotection (42). The Portuguese version of this questionnaire shows good psychometric characteristics and a high proximity with the original version (43). Regarding internal consistency, Cronbach's alphas ranged from 0.60 - 0.90 .

EMBU-C $(44,45)$ assesses children's perceptions about parenting styles using 32 items with 4 points Likert scales. Factorial structure of the Portuguese version replicates the original version with three factors: Emotional Support, Rejection and Attempt to Control (45). Cronbach's alphas ranged from $0.62-0.85(45)$ and similar values were found for this research $(0.51 \leq \alpha \leq 0.88)$.

EMBU-P $(46,47)$ is an instrument that aims to assess parents' self-perceptions regarding their parenting styles, organized in the same three dimensions (emotional support, rejection and attempt to control). Regarding internal consistency, acceptable Cronbach's alphas were found (ranging from $0.58-0.82$ ).
To avoid confusion between the several instruments used to assess parenting styles, we used the following terminology: "memories of upbringing" to refer to EMBU, “children's perceptions" to refer to EMBU-C and "parents' representations" to refer to EMBU-P.

Child Behavior Checklist (CBCL) assesses behavioral and emotional problems and competencies in children and adolescents according to the information provided by their parents or caregivers $(48,49)$. Items were carefully chosen to represent the most frequent children's pathologies as well as indexes showing high correlations with other questionnaires completed by parents regarding general psychopathology (49). Studies in several cultures revealed good internal consistency $(0.61 \leq \alpha \leq 0.83)$. In the present study, Cronbach's alpha ranged from 0.55-0.94, except for the subscale of somatic complaints, which was re$\operatorname{moved}(\alpha=0.43)$.

\section{Results}

Hypotheses were tested using the multiple hierarchical linear regression analysis. As predictor variables, we used socio-demographic children's variables, family variables and children as well as the parents' perceptions regarding parenting styles. As criterion variables, each one of the CBCL's subscales was used individually. Noncontinuous scales were recoded to dichotomous scales (0 or 1). To avoid multicollinearity, Tolerance ( $>0.1)$ and VIF (< 10) were tested. According to the Durbin-Watson's statistic $(\mathrm{d} \sim 2)$, errors are random and independent. The analysis with Kolmogorov-Smirnov, Shapiro-Wilk and Normal QQ Plots showed that the data's distributions do not prevent statistical analysis with linear regressions.

\subsection{Testing Hypothesis 1}

In linear hierarchical regression analysis, four models were considered: Model 1, individual factors (age, gender, education and intellectual level); Model 2, family factors (socio-economic status - SES, parents' education, parents' marital status, parents' occupational status and number of siblings); Model 3, EMBU-P's subscales and Model 4, EMBU-C's subscales.

According to results of the regression analysis, all CBCL's subscales can be explained by family factors and most of these indexes are also explained by individual factors.

As can be seen in Table 1 and contrary to hypothesis 1, when considering all these factors, children's perceptions about maternal parenting styles (Model 4) only significantly increase the explanation of the variance of Hyperactivity/Attention index. However, if we consider the 
representations of parents regarding their own parenting styles (Model 3), several CBCL's indexes of psychopathology (aggressiveness, anxiety, obsessive/schizoid) present a significant change of the explained variance.

Thus, results indicate that, among other factors, representations of parents regarding their own parenting styles have an important role in explaining child psychopathology, being consistent with hypothesis 1 .

In a more detailed analysis for each one of the indexes of psychopathology (Table 2), and through the linear regression lines, we can say that problems such as aggressiveness, anxiety and obsessive/schizoid are associated with the children feeling as if they are being rejected by their parents while hyperactivity/attention is related to the children feeling less emotional support received from mothers, which is consistent with studies indicating that less adaptive parenting styles lead to psychopathological manifestations.

It thus appears that children's psychopathological manifestations are mainly associated with parental representations involving rejecting behavior towards children or in the case of hyperactivity/attention with children's perceptions of less emotional support provided by mothers.

\subsection{Testing Hypothesis 2}

In the linear hierarchical regression analysis, the same first three models were considered, however, now Model 4 becomes complete with the addition of the subscales of EMBU- My Memories of Upbringing.

According to Table 3, even considering the individual and family factors as well as the parents' representations regarding their parenting styles:

- Mothers' childhood memories regarding parenting styles of their own mothers (Model 4) significantly contribute to the explanation of the variance of aggressiveness, hyperactivity/attention, depression, social problems and total of child psychopathology indexes;

- Fathers' childhood memories regarding parenting styles of their own mothers (Model 4) significantly contribute to the explanation of the variance of the opposition/immaturity, hyperactivity/attention and isolation indexes;

- Mothers' childhood memories regarding parenting styles of their own fathers (Model 4) significantly contribute to the explanation of the variance of aggressiveness, hyperactivity/attention, depression, social problems, isolation and total of child psychopathology indexes;

- Fathers' childhood memories regarding parenting styles of their own fathers (Model 4) significantly contribute to the explanation of the variance of the opposition/immaturity, aggressiveness and hyperactivity/attention indexes.

Thus, as embodied in hypothesis 2, parents' childhood memories regarding parenting styles play an important role in the explanation of children's psychopathology.

A more detailed analysis (Table 4), based on regression lines, has shown that in general, as described in literature and previously mentioned, when parents' memories regarding their own parents' styles show more adjusted behaviors (e.g., greater emotional support and less overprotection) the psychopathology indexes of their children tend to be lower.

\section{Discussion}

\subsection{Parenting Styles and Children's Psychopathology}

The role of parenting on the children's psychological well-being has been studied by many authors over several decades. Literature suggests an association between less adaptive parenting styles and child psychopathology but while some authors highlight the external behaviors, others prefer to highlight internal behaviors (14-20).

Our results indicate that, even after controlling the effect of individual and family variables, parenting styles do contribute for the explanation of the statistical variance of aggressiveness, anxiety and obsessive/schizoid indexes (through the parents' representations regarding their own parenting styles) and hyperactivity/attention (through the perception of children regarding the parenting styles of their mothers). It is interesting to note that in spite the fact that the increase of the explanation of the variance of the index of social problems $(\mathrm{P}=0.052)$ and the total psychopathology $(\mathrm{P}=0.053)$ did not reach the statistically significant values, they remain very close to the recommended value $(\mathrm{P}<0.05)$.

Thus, it is considered that these results are consistent with the aforementioned studies arguing that parenting styles play a key role in children's psychopathological manifestations.

The relationship found between children's psychopathology and their parents' representations regarding rejecting behavior towards children or, in the case of hyperactivity/attention with perceptions of children on less emotional support provided by mothers, comes in line with results obtained by other authors. Rejection and lack of parental support have previously been described as causing external and internal problems (20). Child psychopathology tends to be associated to less emotional support and greater overprotection/rejection (50).

Although Gecas et al. (51) already registered discrepancies between parents' and children's perceptions regarding parental investment, it is nonetheless interesting to 
Table 1. Linear Regression: Psychopathological Indexes Explained by Parenting Styles

\begin{tabular}{|c|c|c|c|c|c|c|c|c|c|}
\hline \multirow[t]{2}{*}{ Model } & \multirow[t]{2}{*}{$\mathbf{R}$} & \multirow[t]{2}{*}{$\mathrm{R}^{2}$} & \multirow[t]{2}{*}{ Adjusted $\mathrm{R}^{2}$} & \multirow{2}{*}{$\begin{array}{l}\text { SE of the } \\
\text { Estimate }\end{array}$} & \multicolumn{5}{|c|}{ Change Statistics } \\
\hline & & & & & $\mathrm{R}^{2}$ Change & F Change & dfi & df2 & Sig. F Change \\
\hline \multicolumn{10}{|c|}{ Index of aggressiveness } \\
\hline 1 & 0.357 & 0.127 & 0.073 & 3.372 & 0.127 & 2.367 & 4 & 65 & 0.062 \\
\hline 2 & 0.759 & 0.575 & 0.467 & 2.557 & 0.448 & 5.805 & 10 & 55 & 0.000 \\
\hline 3 & 0.813 & 0.661 & 0.550 & 2.351 & 0.085 & 4.367 & 3 & 52 & 0.008 \\
\hline 4 & 0.824 & 0.680 & 0.549 & 2.353 & 0.019 & 0.966 & 3 & 49 & 0.416 \\
\hline \multicolumn{10}{|c|}{ Index of hyperactivity/attention } \\
\hline 1 & 0.435 & 0.189 & 0.139 & 2.547 & 0.189 & 3.795 & 4 & 65 & 0.008 \\
\hline 2 & 0.766 & 0.588 & 0.483 & 1.975 & 0.398 & 5.310 & 10 & 55 & 0.000 \\
\hline 3 & 0.784 & 0.614 & 0.488 & 1.964 & 0.027 & 1.201 & 3 & 52 & 0.319 \\
\hline 4 & 0.823 & 0.677 & 0.546 & 1.851 & 0.063 & 3.193 & 3 & 49 & 0.032 \\
\hline \multicolumn{10}{|c|}{ Index of anxiety } \\
\hline 1 & 0.496 & 0.246 & 0.200 & 1.823 & 0.246 & 5.302 & 4 & 65 & 0.001 \\
\hline 2 & 0.796 & 0.634 & 0.540 & 1.381 & 0.388 & 5.819 & 10 & 55 & 0.000 \\
\hline 3 & 0.848 & 0.720 & 0.628 & 1.242 & 0.086 & 5.327 & 3 & 52 & 0.003 \\
\hline 4 & 0.868 & 0.754 & 0.654 & 1.199 & 0.034 & 2.271 & 3 & 49 & 0.092 \\
\hline \multicolumn{10}{|c|}{ Index of obsessive/schizoid } \\
\hline 1 & 0.405 & 0.164 & 0.113 & 1.823 & 0.164 & 3.196 & 4 & 65 & 0.019 \\
\hline 2 & 0.776 & 0.602 & 0.501 & 1.368 & 0.438 & 6.054 & 10 & 55 & 0.000 \\
\hline 3 & 0.824 & 0.678 & 0.573 & 1.265 & 0.076 & 4.111 & 3 & 52 & 0.011 \\
\hline 4 & 0.843 & 0.711 & 0.593 & 1.235 & 0.033 & 1.842 & 3 & 49 & 0.152 \\
\hline
\end{tabular}

note that, according to our results, parents' representations regarding their own parenting styles have a greater capacity to explain children's psychopathology than the children's perceptions regarding parenting styles. Besides the fact that these instruments assess the same dimensions, we should not forget that CBCL is a questionnaire answered by parents and therefore it is natural to get a bigger agreement with EMBU-P (also answered by parents) than with EMBU-C.

Another fact that is equally interesting is that the children's perception of parenting styles starring the father show highly significant positive correlations with parenting styles perpetuated by the mother, which relates to Pereira et al. (20), under which, children tend to perceive similar parental profiles for both parents.

The fact that family factors assume a high and generalized capacity to explain children's psychopathology is in line with Ruchkin et al. (12) who recognized that, although parenting styles are an important etiological factor for behavioral problems, they should be regarded as part of a more complex system. As advocated by Kendler (52), there are ample evidences that the pathways to psychopathology involve causal processes that operate at macro and micro levels, inside and outside of the individual and whose understanding requires a biological, psychological and sociocultural framework.
5.2. Grandparents' Parenting Styles and Children's Psychopathology

According to our results, the explanatory power of parenting styles regarding the psychopathology of children is not limited to representations of parents regarding their own parenting styles and to perceptions of children regarding parenting styles, extending also to memories of parents with regards to parenting styles of their own parents. Based on the results of the present study, children's psychopathology can be explained by the childhood memories of parents in respect to parenting styles.

Even after considering the results of EMBU-P, the childhood memories regarding parenting styles explain the variance of the psychopathology indexes of CBCL (except for the anxiety index and the obsessive/schizoid index).

Furthermore, multiple regression analyzes carried out by Lundberg et al. (53) showed that parenting styles are more strongly determined by the personality of the parents than by children's personality.

It seems to conclude that, regarding the children's psychopathological manifestations, the explanatory power allowed by EMBU-My Memories of Upbringing exceeds both the EMBU-P and the EMBU-C.

Nonetheless, we should note that bigger rejection (in parents' memories) associates with lower levels of children's psychopathology. It is believed that two aspects can explain this inverse relationship between rejection 
Table 2. Impact of Parenting Styles upon Children's Psychopathology

\begin{tabular}{|c|c|c|c|c|c|c|c|c|c|}
\hline \multirow[t]{2}{*}{ Indexes of Psychopathology } & \multicolumn{3}{|c|}{ EMBU-P } & \multicolumn{3}{|c|}{ EMBU-C M } & \multicolumn{3}{|c|}{ EMBU-C F } \\
\hline & ES & Rej & AC & ES & Rej & AC & ES & Rej & AC \\
\hline \multicolumn{10}{|l|}{ Opposition/immaturity } \\
\hline Aggressiveness & & + & & & & & & & \\
\hline Hyperactivity/attention & & & & - & & & & & \\
\hline \multicolumn{10}{|l|}{ Social problems } \\
\hline \multicolumn{10}{|l|}{ Isolation } \\
\hline Anxiety & & + & & & & & & & \\
\hline Obsessive/schizoid & & + & & & & & & & \\
\hline \multicolumn{10}{|l|}{ Total of psychopathology } \\
\hline
\end{tabular}

Table 4. Parents' Childhood Memories Regarding Parenting Styles Upon Children’s Psychopathology

\begin{tabular}{|c|c|c|c|c|c|c|c|c|c|c|c|c|}
\hline \multirow[t]{2}{*}{ Indexes of Psychopathology } & \multicolumn{3}{|c|}{$\mathbf{M} \rightarrow \mathbf{M}$} & \multicolumn{3}{|c|}{$\mathbf{F} \rightarrow \mathbf{M}$} & \multicolumn{3}{|c|}{$\mathbf{M} \rightarrow \mathbf{F}$} & \multicolumn{3}{|c|}{$\mathbf{F} \rightarrow \mathbf{F}$} \\
\hline & ES & Rej & Op & ES & Rej & Op & ES & Rej & op & ES & Rej & Op \\
\hline Opposition/Immaturity & & & & & & + & & & & - & - & + \\
\hline Aggressiveness & - & - & & & & & - & - & & + & & \\
\hline Hyperactivity/Attention & - & - & & - & - & + & & - & & - & - & \\
\hline Depression & - & - & & & & & - & - & & & & \\
\hline Social problems & - & - & & & & & & & - & & & \\
\hline Isolation & & & & & & & & - & & & & \\
\hline \multicolumn{13}{|l|}{ Anxiety } \\
\hline \multicolumn{13}{|l|}{ Obsessive/Schizoid } \\
\hline Total of psychopathology & - & - & & & & & - & - & & & & \\
\hline
\end{tabular}

Abbreviations: $\mathrm{M} \rightarrow \mathrm{M}=$ Mother childhood memories regarding her mother; $\mathrm{F} \rightarrow \mathrm{M}=$ Father childhood memories regarding his mother; $\mathrm{M} \rightarrow \mathrm{F}=\mathrm{Mother}$ childhood memories regarding her father; $\mathrm{F} \rightarrow \mathrm{F}=$ Father childhood memories regarding his father; $\mathrm{ES}=$ Emotional Support; Rej = Rejection; Op = Overprotection; (+) Direct relation (positive slope); (-) Inverse relation (negative slope).

and children's psychopathology and the few exceptions in which the above-mentioned pattern is not verified. Initially, we should not forget that we are studying the impact of parents' childhood memories regarding their own parents in children's psychopathology and that there may be continuities or discontinuities between the parenting styles across generations (39). Parents whose childhood memories regarding their own parents suggest that rejecting parenting styles are possibly creating more adaptive parenting styles (in a certain way, "learning from mistakes") and consequently leading to a reduction of psychopathological levels in their children. In addition, sometimes, there may be false childhood memories of parents that affect the answers to these questionnaires, especially in insecure attachment situations (54).

When comparing the explanatory power of mothers'ffathers' childhood memories in relation to their own mothers/fathers, it appears that the greatest explanatory power focuses on maternal childhood memories regarding their own fathers, explaining six indexes of psychopathology (total of psychopathology, aggressiveness, hyperactivity/attention, depression, social problems and isolation) followed by the mothers' childhood memories regarding their own mothers, explaining five psychopathology indexes (total of psychopathology, aggressiveness, hyperactivity/attention, depression and social 
problems).

However, we cannot fail to mention that, as appearing in the previous case, family factors return to take a leading role in explaining children's psychopathology, which proves consistent with scientific literature. For example, Van IJzendoorn (37) and Kerr et al. (38) conceived a theoretical model of intergenerational transmission that combines biological systems, individual characteristics, contextual factors, socialization experiences and social influence of affective relationships with pairs.

\subsection{Conclusions}

\subsubsection{Parenting Styles and Children's Psychopathology}

According to our results, even after controlling the effects of individual and family variables, parenting styles contribute to the explanation of the statistical variance of aggressiveness, anxiety, obsessive/schizoid and hyperactivity/attention indexes.

Although we cannot completely confirm the hypothesis that the perceptions of children regarding parenting styles give a significant contribution to the explanation of children's psychopathology, the results show the importance of parenting styles, namely through the impact of parental representations in children's psychopathology, which comes in line with what has been cited in the scientific literature.

The fact that, compared to children's perceptions, parents' representations regarding parenting styles have a higher explanatory power for children's psychopathology can be associated into two different aspects: Not only the EMBU-P leaves little explanatory room for EMBU-C but also both EMBU-P and CBCL are self-reported questionnaires, filled out by parents.

In the future, it would be interesting to test this hypothesis by using another instrument different from the CBCL, also quantitative, but without using parental rating to assess the children's psychopathology.

Therefore, it is considered that this research not only highlights the importance of parenting styles, but also contributes to the clarification of the less adaptive parental attitudes and the psychopathologies and how its impact is more significant.

\subsubsection{Grandparents' Parenting Styles and Children's Psy- chopathology}

As previously advanced, results indicate that the explanatory power of parenting styles in relation to childhood psychopathological manifestations is not limited to the perceptions of children or even to their parents' representations regarding their own parenting styles or extending to childhood memories of parents relatively to parent- ing styles performed by their own parents, whose explanatory power comes as even higher.

These results not only confirm the models of intergenerational transmission of parenting styles but also emphasize the role of memories that parents (especially mothers) have regarding parenting styles performed by their own parents (especially maternal grandfathers) upon children's psychopathology. Once again and as stated in the previous case, it is suggested that in future research, childhood psychopathological manifestations should be assessed through another instrument that does not refer to parental rating.

Highlighting the importance of parents' childhood memories regarding parenting styles in the manifestation of children's psychopathology and by concluding that their explanatory power goes beyond both parental representations and children's perceptions regarding parenting styles, this study allows a unique contribution to the understanding of childhood psychopathology.

\section{Footnotes}

Conflict of Interest: The authors of this manuscript declare no potential conflict of interest. The authors declare no relationship with any company whose products or services may be related to the subject matter of the article and that this work has not received any funding.

Funding/Support: No funding was obtained.

Informed Consent: Written informed consent was obtained from parents. Written informed consent was also obtained from the schools' directive boards assuming deontological responsibilities.

Research Involving Human Participants and/or Animals: This article does not contain any studies with animals performed by any of the authors. All procedures performed in studies involving human participants who were in accordance with the ethical standards of the institutional and/or national research committee and with the 1964 Helsinki declaration and its later amendments or comparable ethical standards.

\section{References}

1. Baumrind D. Current patterns of parental authority. Develop Psychol. 1971;4(1):1-103. doi: 10.1037/h0030372.

2. Chan SM, Bowes J, Wyver S. Parenting style as a context for emotion socialization. Early Educ Dev. 2009;20(4):631-56. doi: 10.1080/10409280802541973.

3. Baumrind D. Parental disciplinary patterns and social competence in children. Youth Soc. 1978;9:239-76. 
4. Sroufe LA. From infant attachment to promotion of adolescent autonomy: Prospective, longitudinal data on the role of parents in development. In: Borkowski JD, Ramey SL, Bristol-Power M, editors. Parenting and the child's world: Influences on academic, intellectual, and socioemotional development. New York: Psychology Press; 2002. pp. 187-202.

5. Amato PR. Father-child relations, mother-child relations, and offspring psychological well-being in early adulthood. J Marriage Fam. 1994:1031-42.

6. Amato PR, Ochiltree G. Family resources and the development of child competence. J Marriage Fam. 1986:47-56.

7. Gecas V. Parental behavior and dimensions of adolescent selfevaluation. Sociometry. 1971;34(4):466-82. [PubMed: 5125959].

8. Wilkinson RB. The role of parental and peer attachment in the psychological health and self-esteem of adolescents. $J$ Youth Adolesc. 2004;33(6):479-93.

9. Clayer JR, Ross MW, Campbell RL. Child-rearing patterns and dimensions of personality. Soc Behav Personal Inter J. 1984;12(2):153-6.

10. Belsky J. The determinants of parenting: a process model. Child Dev. 1984;55(1):83-96. [PubMed: 6705636].

11. Ghazinour M, Richter J, Emami H, Eisemann M. Do parental rearing and personality characteristics have a buffering effect against psychopathological manifestations among Iranian refugees in Sweden?. Nord JPsychiatry. 2003;57(6):419-28. doi:10.1080/08039480310003434. [PubMed: 14630547].

12. Ruchkin VV, Eisemann M, Koposov RA, Hägglöf B. Family functioning, parental rearing and behavioural problems in delinquents. Clin Psychol Psychother. 2000;7(4):310-9.

13. Eisemann M. Praticas educativas de los padres y psicopatologia. Revista Psiquiatria Fac Med Barna. 1988;15:243-54.

14. Berkien M, Louwerse A, Verhulst F, van der Ende J. Children's perceptions of dissimilarity in parenting styles are associated with internalizing and externalizing behavior. Eur Child Adolesc Psychiatry. 2012;21(2):79-85. doi: 10.1007/s00787-011-0234-9. [PubMed: 22222568].

15. Caron A, Weiss B, Harris V, Catron T. Parenting behavior dimensions and child psychopathology: specificity, task dependency, and interactive relations. J Clin Child Adolesc Psychol. 2006;35(1):34-45. doi: 10.1207/s15374424jccp3501_4. [PubMed:16390301].

16. Chen X, Liu M, Li D. Parental warmth, control, and indulgence and their relations to adjustment in Chinese children: a longitudinal study. J Fam Psychol. 2000;14(3):401-19. [PubMed: 11025932].

17. Dwairy MA. Parental inconsistency versus parental authoritarianism: Associations with symptoms of psychological disorders. J Youth Adolesc. 2008;37(5):616-26.

18. Dwairy M. Parental inconsistency: A third cross-cultural research on parenting and psychological adjustment of children.J Child Fam Stud. 2010;19(1):23-9.

19. Muris P, Bögels S, Meesters C, van der Kamp N, van Oosten A. Parental rearing practices, fearfulness, and problem behaviour in clinically referred children. Pers Individ Dif. 1996;21(5):813-8. doi: 10.1016/01918869(96)00119-5.

20. Pereira AIF, Canavarro C, Cardoso MF, Mendonça D. Patterns of Parental Rearing Styles and Child Behaviour Problems among Portuguese School-Aged Children. J Child Fam Stud. 2008;18(4):454-64. doi: 10.1007/s10826-008-9249-3.

21. Roelofs J, Meesters C, Ter H, Bamelis M, Muris P. On the links between attachment style, parental rearing behaviors and internalizing and externalizing problems in non-clinical children. J Child Fam Stud. 2006;15(3):331-44. doi: 10.1007/s10826-006-9025.

22. Belsky J, Pasco Fearon RM, Bell B. Parenting, attention and externalizing problems: testing mediation longitudinally, repeatedly and reciprocally. J Child Psychol Psychiatry. 2007;48(12):1233-42. doi: 10.1111/j.1469-7610.2007.01807.x. [PubMed: 18093029].

23. Rosa-Alcázar AI, Parada-Navas JL, Rosa-Alcázar A. Síntomas psicopatológicos en adolescentes españoles: relacion con los estilos parentales percibidos y la autoestima. Anales de psicologia.
2014;30(1):133-42

24. Perris C. Linking the experience of dysfunctional parental rearing with manifest psychopathology: A theoretical framework. Parenting Psychopathol. 1994:3-32.

25. Caraveo MEM, Guzmán LH, Villalobos JA, Barrón VP, Sandoval MR. Datos psicométricos del EMBU-I" Mis memorias de crianza" como indicador de la percepción de crianza en una muestra de adolescentes de la Ciudad de Mexico. Salud Mental. 2007;30(2):58-66.

26. Aluja A, del Barrio V, Garcia LF. Do parents and adolescents differ in their perceptions of rearing styles? Analysis of the EMBU versions for parents and adolescents. Scand J Psychol. 2006;47(2):103-8. doi: 10.1111/j.1467-9450.2006.00497.x. [PubMed: 16542352].

27. Martin G, Bergen HA, Roeger L, Allison S. Depression in young adolescents: investigations using 2 and 3 factor versions of the Parental Bonding Instrument. J Nerv Ment Dis. 2004;192(10):650-7.

28. Heider D, Matschinger H, Bernert S, Alonso J, Angermeyer MC. Relationship between parental bonding and mood disorder in six European countries. Psychiat Res. 2006;143(1):89-98.

29. Iglesias B, Triñanes ER. Estilos parentales percibidos, psicopatología y personalidad en la adolescencia. Revista de psicopatologia y psicología clinica. 2009;14(2):63-77.

30. Russell JD, Kopec-Schrader E, Rey JM, Beumont PJ. The Parental Bonding Instrument in adolescent patients with anorexia nervosa. Acto Psychiatr Scand. 1992;86(3):236-9. [PubMed:1414420].

31. Pons J, Berjano E. Análisis de los estilos parentales de socialización asociados al abuso de alcohol en adolescentes.. Psicothema. 1997;9:609-17.

32. Villar P, Luengo MA, Gomez JA, Romero E. Una propuesta de evaluacion de variables en la prevencion de la conducta problema en la adolescencia. Psicothema. 2003;5:581-8.

33. Lindahl KM. Family process variables and children's disruptive behavior problems. J Fam Psychol. 1998;12(3):420.

34. Kovan NM, Chung AL, Sroufe LA. The intergenerational continuity of observed early parenting: A prospective, longitudinal study. Dev Psychol. 2009;45(5):1205.

35. Conger RD, Belsky J, Capaldi DM. The intergenerational transmission of parenting: closing comments for the special section. Dev Psychol. 2009;45(5):1276-83. doi:10.1037/a0016911. [PubMed: 19702391].

36. Belsky J, Jaffee SR, Sligo J, Woodward L, Silva PA. Intergenerational transmission of warm-sensitive-stimulating parenting: A prospective study of mothers and fathers of 3-year-olds. Child Dev. 2005;76(2):384-96. doi: 10.1111/j.1467-8624.2005.00852.x.

37. Van Ijzendoorn MH. Intergenerational transmission of parenting: A review of studies in nonclinical populations. Dev Rev. 1992;12(1):76-99.

38. Kerr DCR, Capaldi DM, Pears KC, Owen LD. A prospective three generational study of fathers' constructive parenting: Influences from family of origin, adolescent adjustment, and offspring temperament. Dev Psychol. 2009;45(5):1257.

39. Campbell J, Gilmore L. Intergenerational continuities and discontinuities in parenting styles. Australian J Psychol. 2007;59(3):140-50.

40. Raven J, Raven JC, Court JH. Manual for raven's progressive matrices and vocabulary scales. San Antonio TX: Harcourt Assessment; 2004.

41. Simoes M. O teste das matrizes progressivas coloridas de raven. In Almeida L, Simoes M, Goncalves M, editors. Provas psicologicas em portugal.. Braga: Associacao dos Psicologos Portugueses; 1995. pp. 1 18.

42. Perris C, Jacobsson L, Lindstrom H, von Knorring L, Perris H. Development of a new inventory assessing memories of parental rearing behaviour. Acta Psychiatr Scand. 1980;61(4):265-74. [PubMed: 7446184].

43. Canavarro MC. Relacoes afectivas ao longo do ciclo de vida e saude mental. Coimbra: Quarteto; 2001.

44. Castro J, Toro J, Van der Ende J, Arrindell WA. Exploring the feasibility of assessing perceived parental rearing styles in Spanish children with the EMBU. Int J Soc Psychiatry. 1993;39(1):47-57.[PubMed: 8478163]. 45. Canavarro MC, Pereira AI. A percepcao dos filhos sobre os estilos ed- 
ucativos parentais: A versao portuguesa do EMBU-C. Revista IberoAmericana de Diagnostico e Avaliacao Psicologica. 2007;24:193-210.

46. Castro J, Toro J, Arrindell WA, Van der Ende J, Puig J, Costa S. Perceived parental rearing style in Spanish adolescents, children and parents: three new forms of the EMBU. In: Stefanis CN, Solsatos CR, Ravavilas AD, editors. Psychiatry: a world perspective. 4. Amsterdam: Elsevier; 1990. pp.345-9.

47. Canavarro MC, Pereira AI. A avaliação dos estilos parentais educativos na perspectiva dos pais: A versão portuguesa do EMBU-P. Psicologia: Teoria, Investigacao e Pratica. 2007;2:271-86.

48. Achenbach TM. Integrative guide for the $1991 \mathrm{cbcl} / 4-18$, ysr, and trf profiles. Burlington, VT: Department of Psychiatry, University of Vermont; 1991.

49. Fonseca AC, Simões A, Rebelo JA, Ferreira JA, Cardoso F. Um inventário de competências sociais e de problemas do comportamento em crianças e adolescentes. O Child Behaviour Checklist de Achenbach (CBCL).
1994;12:55-78.

50. Conceicao LSLD. Estilos educativos parentais (EMBU-A), sintomatologia depressiva/ansiosa, stress e autoestima, numa amostra de adolescentes. Coimbra: Tese de Mestrado apresentada no ISMT.; 2012.

51. Gecas V, Schwalbe ML. Parental Behavior and Adolescent Self-Esteem. J Marriage Fam. 1986;48(1):37. doi:10.2307/352226.

52. Kendler KS. Explanatory models for psychiatric illness. Am JPsychiatry. 2008,165(6):695-702. doi: 10.1176/appi.ajp.2008.07071061. [PubMed: 18483135].

53. Lundberg $M$, Perris $C$, Adolfsson R. Family environment and personality: perceived parenting and the role of personality. Clin Psychol Psychother. 2000;7(4):267-74. doi: 10.1002/10990879(200010)7:4<267::aid-cpp258>3.3.co;2-j.

54. Qin J, Ogle CM, Goodman GS. Adults' memories of childhood: true and false reports. J Exp Psychol Appl. 2008;14(4):373-91. doi: 10.1037/a0014309. [PubMed: 19102620]. 
Table 3. Explanation of Children's Psychopathology Trough Parents' Childhood Memories Regarding Parenting Styles

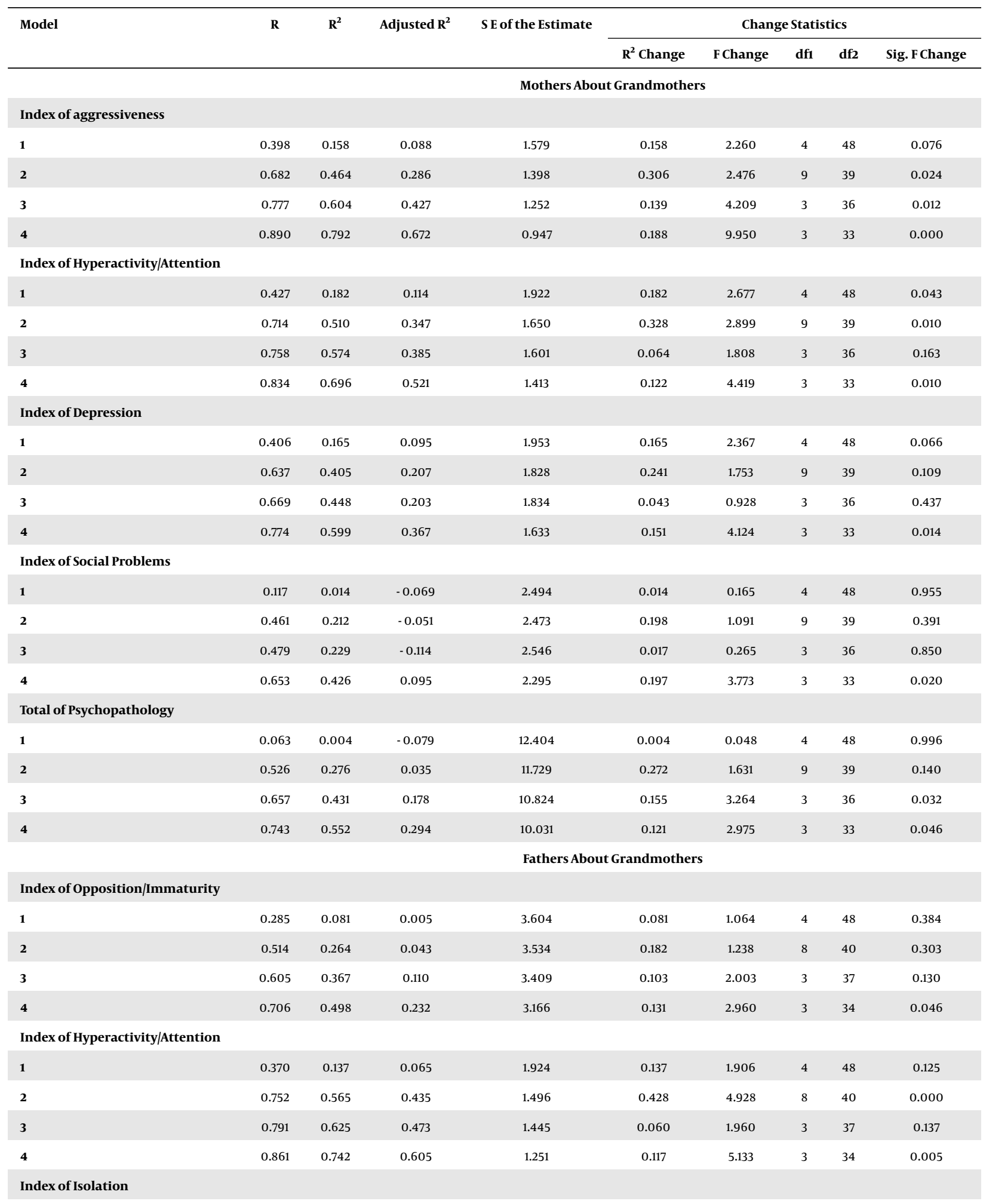




\begin{tabular}{|c|c|c|c|c|c|c|c|c|c|}
\hline 1 & 0.444 & 0.197 & 0.130 & 1.407 & 0.197 & 2.951 & 4 & 48 & 0.029 \\
\hline 2 & 0.641 & 0.411 & 0.234 & 1.321 & 0.214 & 1.813 & 8 & 40 & 0.103 \\
\hline 3 & 0.749 & 0.561 & 0.383 & 1.186 & 0.150 & 4.205 & 3 & 37 & 0.012 \\
\hline 4 & 0.811 & 0.657 & 0.475 & 1.093 & 0.096 & 3.180 & 3 & 34 & 0.036 \\
\hline
\end{tabular}

Mothers About Grandfathers

Index of Aggressiveness

\begin{tabular}{|c|c|c|c|c|c|c|c|c|c|}
\hline 1 & 0.422 & 0.178 & 0.105 & 1.592 & 0.178 & 2.443 & 4 & 45 & 0.060 \\
\hline 2 & 0.687 & 0.472 & 0.282 & 1.427 & 0.294 & 2.229 & 9 & 36 & 0.043 \\
\hline 3 & 0.784 & 0.615 & 0.428 & 1.273 & 0.143 & 4.073 & 3 & 33 & 0.014 \\
\hline 4 & 0.896 & 0.803 & 0.678 & 0.956 & 0.188 & 9.515 & 3 & 30 & 0.000 \\
\hline \multicolumn{10}{|c|}{ Index of Hyperactivity/Attention } \\
\hline 1 & 0.409 & 0.167 & 0.093 & 1.952 & 0.167 & 2.254 & 4 & 45 & 0.078 \\
\hline 2 & 0.739 & 0.547 & 0.383 & 1.610 & 0.380 & 3.349 & 9 & 36 & 0.005 \\
\hline 3 & 0.766 & 0.587 & 0.386 & 1.606 & 0.040 & 1.069 & 3 & 33 & 0.375 \\
\hline 4 & 0.853 & 0.728 & 0.556 & 1.366 & 0.141 & 5.194 & 3 & 30 & 0.005 \\
\hline \multicolumn{10}{|c|}{ Index of Depression } \\
\hline $\mathbf{1}$ & 0.412 & 0.170 & 0.096 & 2.008 & 0.170 & 2.300 & 4 & 45 & 0.073 \\
\hline 2 & 0.650 & 0.423 & 0.214 & 1.872 & 0.253 & 1.752 & 9 & 36 & 0.113 \\
\hline 3 & 0.693 & 0.480 & 0.229 & 1.855 & 0.058 & 1.224 & 3 & 33 & 0.316 \\
\hline 4 & 0.817 & 0.668 & 0.457 & 1.556 & 0.187 & 5.637 & 3 & 30 & 0.003 \\
\hline \multicolumn{10}{|c|}{ Index of Social Problems } \\
\hline 1 & 0.109 & 0.012 & -0.076 & 2.567 & 0.012 & 0.135 & 4 & 45 & 0.968 \\
\hline 2 & 0.469 & 0.220 & -0.062 & 2.550 & 0.208 & 1.066 & 9 & 36 & 0.410 \\
\hline 3 & 0.481 & 0.231 & -0.141 & 2.644 & 0.011 & 0.164 & 3 & 33 & 0.920 \\
\hline 4 & 0.700 & 0.490 & 0.167 & 2.259 & 0.259 & 5.072 & 3 & 30 & 0.006 \\
\hline \multicolumn{10}{|c|}{ Index of Isolation } \\
\hline 1 & 0.326 & 0.106 & 0.027 & 1.352 & 0.106 & 1.334 & 4 & 45 & 0.272 \\
\hline 2 & 0.593 & 0.351 & 0.117 & 1.288 & 0.245 & 1.511 & 9 & 36 & 0.182 \\
\hline 3 & 0.681 & 0.464 & 0.204 & 1.222 & 0.113 & 2.320 & 3 & 33 & 0.093 \\
\hline 4 & 0.797 & 0.635 & 0.404 & 1.058 & 0.171 & 4.694 & 3 & 30 & 0.008 \\
\hline \multicolumn{10}{|c|}{ Total de Psychopathology } \\
\hline 1 & 0.060 & 0.004 & -0.085 & 12.773 & 0.004 & 0.041 & 4 & 45 & 0.997 \\
\hline 2 & 0.540 & 0.292 & 0.036 & 12.040 & 0.288 & 1.627 & 9 & 36 & 0.144 \\
\hline 3 & 0.656 & 0.431 & 0.155 & 11.273 & 0.139 & 2.689 & 3 & 33 & 0.062 \\
\hline 4 & 0.794 & 0.631 & 0.397 & 9.519 & 0.200 & 5.427 & 3 & 30 & 0.004 \\
\hline
\end{tabular}

Fathers About Grandfathers

\begin{tabular}{|c|c|c|c|c|c|c|c|c|c|}
\hline \multicolumn{10}{|c|}{ Index of Opposition/Immaturity } \\
\hline 1 & 0.340 & 0.116 & 0.039 & 3.483 & 0.116 & 1.507 & 4 & 46 & 0.216 \\
\hline 2 & 0.615 & 0.378 & 0.181 & 3.214 & 0.262 & 2.001 & 8 & 38 & 0.073 \\
\hline 3 & 0.700 & 0.490 & 0.271 & 3.032 & 0.112 & 2.563 & 3 & 35 & 0.070 \\
\hline 4 & 0.820 & 0.672 & 0.487 & 2.544 & 0.182 & 5.907 & 3 & 32 & 0.003 \\
\hline \multicolumn{10}{|c|}{ Index of Aggressiveness } \\
\hline 1 & 0.597 & 0.356 & 0.300 & 3.126 & 0.356 & 6.359 & 4 & 46 & 0.000 \\
\hline
\end{tabular}




\begin{tabular}{|c|c|c|c|c|c|c|c|c|c|}
\hline 2 & 0.809 & 0.655 & 0.546 & 2.516 & 0.299 & 4.121 & 8 & 38 & 0.001 \\
\hline 3 & 0.837 & 0.700 & 0.571 & 2.446 & 0.045 & 1.744 & 3 & 35 & 0.176 \\
\hline 4 & 0.882 & 0.777 & 0.652 & 2.205 & 0.077 & 3.693 & 3 & 32 & 0.022 \\
\hline \multicolumn{10}{|c|}{ Index of Hyperactivity/Attention } \\
\hline $\mathbf{1}$ & 0.452 & 0.204 & 0.135 & 1.850 & 0.204 & 2.945 & 4 & 46 & 0.030 \\
\hline 2 & 0.758 & 0.575 & 0.441 & 1.487 & 0.371 & 4.146 & 8 & 38 & 0.001 \\
\hline 3 & 0.792 & 0.628 & 0.468 & 1.450 & 0.053 & 1.654 & 3 & 35 & 0.195 \\
\hline 4 & 0.873 & 0.763 & 0.629 & 1.211 & 0.135 & 6.054 & 3 & 32 & 0.002 \\
\hline
\end{tabular}

